\title{
Sustainability evaluation of an electric bus fleet for the urban public transport system of Padova, Italy
}

\author{
M. Andriollo \& A. Tortella \\ Department of Industrial Engineering, University of Padua, Italy
}

\begin{abstract}
The paper analyses the potential benefits deriving from the introduction of an electric battery-supplied bus (EBB) fleet in the urban transportation context of the city of Padova, Italy. Such analysis is carried out in the frame of a business plan focused on the development of recharge/replacement stations located at suitable bus terminals, adopting an optimized strategy to replace and recharge the on-board batteries running low. After an extensive analysis of the actual urban bus fleet, equivalent bus configurations are defined for both diesel and compressed natural gas vehicles, by means of an analytical elaboration of reference driving cycles. Such elaboration also includes the performance deterioration over the vehicle life by applying a derating function to the propulsion system and catalyser efficiencies. Then, the EBBs characteristics and operation are determined by an algorithm aiming at the minimization of the battery investment and operating costs on ten years' service. Finally, the equivalent buses with different length are compared in terms of energy consumptions and pollutant emissions on the same reference routes. Such comparison is carried out by numerical simulations, taking into account both the engine practical behaviour and the battery charge/discharge operation.

Keywords: public transport, internal combustion engine bus, electric battery bus, vehicle simulation, transport pollutant emissions, fuel consumption.
\end{abstract}

\section{Introduction}

Recently, the European Commission (EC) elaborated a roadmap for a competitive and resource efficient transport system, aiming at the achievement of a $60 \%$ emission reduction target by 2050 (EU [1]). Such document promotes, 
among other actions, an urban transport service by buses possibly propelled by more environmentally-friendly engines, activating several funding schemes to overcome high costs of the vehicles and infrastructures, low consumer acceptance and interconnection difficulties among different transport systems.

In spite of relevant measures introduced in the last years to reduce transportrelated air pollution, Italian public bus transportation is far to agree with the European regulations (ASSTRA [2]). Euro 2 and 3 buses are already prevailing in 2011 (about $60 \%$ of the total fleet), but Euro 0 ones still retain a significant share $(\approx 9 \%)$. The improvements since 2007 are mainly due to the growing of the Enhanced Environmental Vehicles (EEVs), to the higher share of compressed natural gas $(\mathrm{CNG})$ and electric vehicles $(+3 \%$ and $1.2 \%$ respectively in comparison with 2007). Yet, further problems must be taken into consideration:

- the average lifetime increases from 9.4 to 10.6 years in the 2007-2011 timespan - possibly worsening gas emissions in the next operating period;

- the number of passengers is almost unvaried (-0.2\%) in the same period confirming poor attractiveness of public transport (ISTAT [3]);

- the number of the seats $\cdot \mathrm{km} / \mathrm{inh}$ abitant is decreasing by about $5.4 \%$ - most likely in relation to the high cost needed for the bus fleet renewal.

The 2008 report of the regional environmental agency (ARPAV [4]) evidence the relevant contribution of heavy-duty vehicles - including urban buses - to the emissions in the Padova urban area traffic in 2008, amounting to $18 \%$ of the total, with a maximum of $42 \%$ for $\mathrm{NO}_{\mathrm{x}}$ pollutants.

Even if the tram network led to an appreciable improvement in accessibility and a reduction of private car circulation since 2007, $\mathrm{PM}_{10}$ and $\mathrm{NO}_{2}$ still exceeded daily limits $\left(35 \mu \mathrm{g} / \mathrm{m}^{3}\right.$ and $45 \mu \mathrm{g} / \mathrm{m}^{3}$, respectively, from ARPAV data in 2013).

Despite the slightly constant improvement since 2009, like other northern Italian mid-sized cities, these data evidence the need to step up the adoption of less polluting technologies (e.g., electric or hybrid), even for public bus transportation. Low-impact buses could possibly benefit also by higher route flexibility, better compatibility with historical and scenic downtown character, lower noise and easier adjustment of capacity to variations of the user demand. On the other side, several limitations may affect innovative clean technologies as well, affecting the investment payback: limitation in EBB capacity and operating range, battery lifetime, for instance.

In order to improve battery efficiency and duration, an optimized management of an EBBs fleet is presented in the paper, to be applied in an urban transportation context of the city of Padova: with stations for battery recharging and fast swap envisaged at the route terminals. After an optimal strategy for the battery selection and management is determined, the sustainability of such system is evaluated by a suitable methodology and compared with internal combustion engine (ICE) buses, relying of the definition of "equivalent bus" configurations, including the powertrain performance deterioration over the vehicle life. The operation of the different vehicle types on reference urban 
driving cycles is simulated to assess the specific energy consumption and pollutant emissions of $8 \mathrm{~m}$ and $11 \mathrm{~m}$ long vehicles, widely in such context.

\section{Public urban transport system in Padova}

The public urban transport (PUT) of Padova is managed by the company APSAzienda Padova Servizi - Holding Spa. It consists of 74 sectors distributed on 24 routes for a total operating distance of $7227000 \mathrm{~km} /$ year. The main routes (operating distance $>150000 \mathrm{~km} /$ year) and corresponding bus allocation are reported in Table 1. The analysis of data in the APS sustainability report [5] suggests that:

- $\quad \mathrm{CNG}$ fuelled buses have been gradually replacing the diesel ones (103 against 27 new acquisitions in the last ten years), resulting predominant both in terms of route assignments and travelled $\mathrm{km} / \mathrm{year}(+50 \%)$; as a result, the total emissions were reduced (as shown in Fig. 1);

- the average fuel consumptions are $2.21 \mathrm{~km} / 1$ and $1.3 \mathrm{~km} / \mathrm{m}^{3}$ for diesel and CNG fuelled buses, respectively; such values, approximately agreeing with analogous city public transport systems, are consistent with the low average speed $(\cong 14 \mathrm{~km} / \mathrm{h})$, caused by traffic congestion and circulation bottlenecks, but are primarily due to the long average operation life (11.4 years);

- in spite of a remarkably lower fuel cost per $\mathrm{km}(0.3 € / \mathrm{km}$ instead of 0.58 $€ / \mathrm{km}$ (APS [5])), the overall operational costs per $\mathrm{km}$ for $\mathrm{CNG}$ buses can be higher than the diesel ones, due to maintenance, fuel conditioning and service (e.g., compare routes \#5 and \#24 in Table 1, with a similar service).

A reliable model of the real bus operation is therefore fundamental to accurately estimating both the fuel consumption and the actual operational costs.

Table 1: Data of the main urban bus routes $\left(N_{r}\right.$ : route number, $L$ : bus length, $n_{\text {bus }}$ : number of buses; $D$ : travel distance, $c_{k m}$ : operational cost).

\begin{tabular}{|c|c|c|c|c|c|}
\hline$N_{r}$ & $L(\mathrm{~m})$ & Fuel & $n_{\text {bus }}$ & $D(\mathrm{~km})$ & $c_{k m}(€ / \mathrm{km})$ \\
\hline 3 & 12 & CNG & 5 & 397578 & 0.41 \\
\hline 4 & 12 & Diesel & 4 & 175820 & 0.39 \\
\hline 5 & 12 & CNG & 6 & 383685 & 0.44 \\
\hline 6 & 12 & CNG & 7 & 298636 & 0.44 \\
\hline 7 & 12 & CNG & 4 & 239048 & 0.31 \\
\hline 9 & 11 & Diesel & 7 & 290719 & 0.37 \\
\hline 10 & 18 & CNG & 5 & 326981 & 0.66 \\
\hline 11 & 12 & CNG & 6 & 354878 & 0.32 \\
\hline
\end{tabular}

\begin{tabular}{|c|c|c|c|c|c|}
\hline$N_{r}$ & $L(\mathrm{~m})$ & Fuel & $n_{\text {bus }}$ & $D(\mathrm{~km})$ & $c_{k m}(€ / \mathrm{km})$ \\
\hline 12 & 12 & CNG & 6 & 374726 & 0.45 \\
\hline 13 & 12 & CNG & 8 & 404730 & 0.37 \\
\hline 15 & 11 & CNG & 6 & 348943 & 0.29 \\
\hline 16 & 12 & CNG & 7 & 369440 & 0.35 \\
\hline 18 & 18 & CNG & 7 & 362280 & 0.56 \\
\hline 22 & 12 & CNG & 8 & 567369 & 0.46 \\
\hline 24 & 12 & Diesel & 6 & 368861 & 0.42 \\
\hline DP & 8 & Diesel & 5 & 230674 & 0.22 \\
\hline
\end{tabular}

\section{Equivalent ICE bus}

In order to consider all the bus characteristics and related actual operational data, equivalent vehicle configurations for each bus length and fuel type are defined 


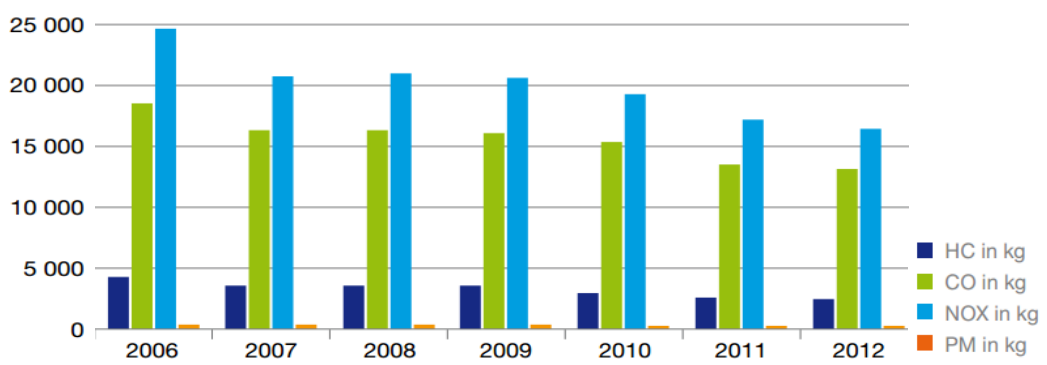

Figure 1: Estimated emissions of the overall APS bus fleet.

by averaging the rated data on the yearly travel distance (Table 2). The code implementation enables to calculate the specific fuel consumption $d_{f}$ and the generic pollutant emission $X$, being the drive cycle defined. The high age of the equivalent vehicle is taken into account by applying a penalty correction to both the reference powertrain (engine and mechanical transmission) and antipollution catalyst efficiencies. Decreasing rates of $-1.5 \% /$ year for powertrain efficiency and $-0.5 \%$ year for the catalyst efficiency are assumed, derived by elaborating test bench data, and can be also adopted to determine $d_{f}$ and $X$ for subsequent operating years. The efficiency dependence on instantaneous output power is defined according on the maximum ICE power $P_{M, I C E}$. A typical profile derived from experimental data is shown Fig. 2: efficiency appreciably decreases when the output power falls below the $70 \%$ of the maximum value.

Table 2: Equivalent ICE bus characteristics.

\begin{tabular}{|c|c|c|c|c|c|c|c|c|c|c|}
\hline \multirow{2}{*}{$\begin{array}{l}\text { Length } \\
L(\mathrm{~m})\end{array}$} & \multicolumn{2}{|c|}{$\begin{array}{l}\text { Fuel consumption } \\
d_{f}^{*}\left(\mathrm{~km} / \mathrm{l}, \mathrm{km} / \mathrm{m}^{3}\right)\end{array}$} & \multicolumn{2}{|c|}{$\begin{array}{c}\text { Max ICE power } \\
P_{M, I C E}(\mathrm{~kW}) \\
\end{array}$} & \multicolumn{2}{|c|}{$\begin{array}{c}\text { Age } \\
Y(\text { years })\end{array}$} & \multicolumn{2}{|c|}{$\begin{array}{c}\text { Passengers } \\
N_{p}\end{array}$} & \multicolumn{2}{|c|}{$\begin{array}{c}\text { Tare } \\
M_{t}(\mathrm{~kg})\end{array}$} \\
\hline & Diesel & $\mathrm{CNG}$ & Diesel & $\mathrm{CNG}$ & Diesel & $\mathrm{CNG}$ & Diesel & $\mathrm{CNG}$ & iesel & $\mathrm{CNG}$ \\
\hline 8 & 2.64 & - & 130 & - & 13 & - & 55 & - & 6744 & - \\
\hline 11 & 7 & 48 & 193 & 213 & 14 & 2 & 99 & 83 & 10793 & 13190 \\
\hline 12 & 2.18 & 36 & 203 & 180 & 10 & 7 & 102 & 94 & \begin{tabular}{|l|l}
10879 \\
\end{tabular} & 12403 \\
\hline 18 & 1.59 & 0.96 & 198 & 232 & 12 & 7 & 143 & 148 & 17990 & 19664 \\
\hline
\end{tabular}

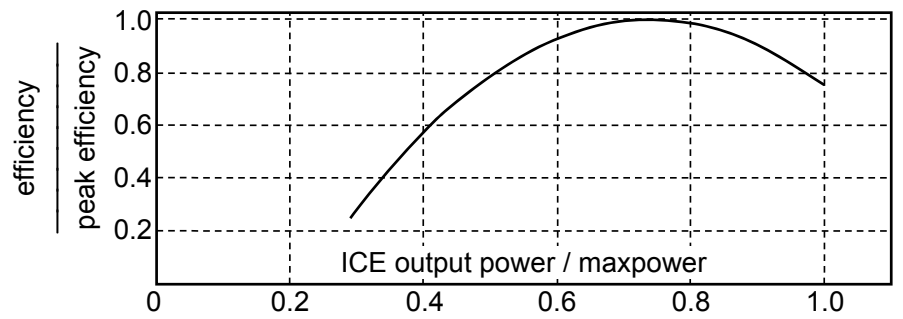

Figure 2: ICE per unit efficiency as a function of the per unit output power.

The corrected peak efficiency, taking into account the bus age, is 0.35 for $8 \mathrm{~m}$ long buses and 0.38 for the other ones. Finally, the motion resistances and then 
the total consumption during the driving cycle are evaluated according to the total vehicle mass $M_{\text {bus }}=M_{\text {pass }}+M_{t}+M_{I C E}$ ( $M_{\text {pass }}$ : payload mass $-35 \%$ total capacity ratio assumed in the following, according to the average data checked by APS -, $M_{I C E}$ : propulsion system mass). The rolling resistance $F_{r}$ and the aerodynamic drag $F_{w}$ forces are then expressed as [6] ( $g$ gravity acceleration, $f_{0}$ friction coefficient, $\rho$ air density, $C_{D}$ aerodynamic drag coefficient, $A_{f}$ vehicle frontal section and $v$ vehicle speed):

$$
F_{r}=M_{b u s} g f_{0}, \quad F_{w}=1 / 2 \rho A_{f} C_{D} v^{2}
$$

The instantaneous ICE power $p_{I C E}$ and the corresponding fuel consumption $d_{f}$ (in $\mathrm{km} / 1$ or $\mathrm{km} / \mathrm{m}^{3}$ ) related to a given driving cycle are determined by:

$p_{I C E}=\frac{1}{\eta_{t}}\left[M_{\text {bus }} \cdot(1+\varepsilon) \frac{\mathrm{d} v}{\mathrm{~d} t}+F_{r}+F_{w}\right] \cdot v+P_{a u x}, d_{f}=\sigma_{f} \cdot D / \int_{0}^{T}\left(p_{I C E} / \eta_{I C E}\right) d t$

with $\eta_{t}$ and $\eta_{I C E}$ mechanical transmission and ICE efficiencies, $\varepsilon=0.05$ coefficient taking into account of the rotating part inertia, $P_{\text {aux }}=k_{\text {aux }} \cdot P_{M, I C E}$ power used to supply the mechanical auxiliary loads $\left(k_{a u x}=0.1\right), \sigma_{f}$ fuel specific energy (36 MJ/1 for diesel, $38 \mathrm{MJ} / \mathrm{m}^{3}$ for $\mathrm{CNG}$ ) and $\eta$ total powertrain efficiency. During decelerations, a condition $p_{I C E}=P_{a u x}$ is assumed.

The motion resistance parameters are evaluated by applying (2) to three reference driving cycles (routes DP, \#9 and \#3 in Table 1) representative of urban routes for the $8 \mathrm{~m}$ long bus, of a mixed operation route for the 11-12 $\mathrm{m}$ long buses and of a predominant extra-urban route for the $18 \mathrm{~m}$ long bus.

The actual $v(t)$ profiles have been determined elaborating the GPS data recorded by an Android app (Google $C$ My Tracks) during the actual bus operation. As an example, the elaborated profile for the route DP is shown in Fig. 3.

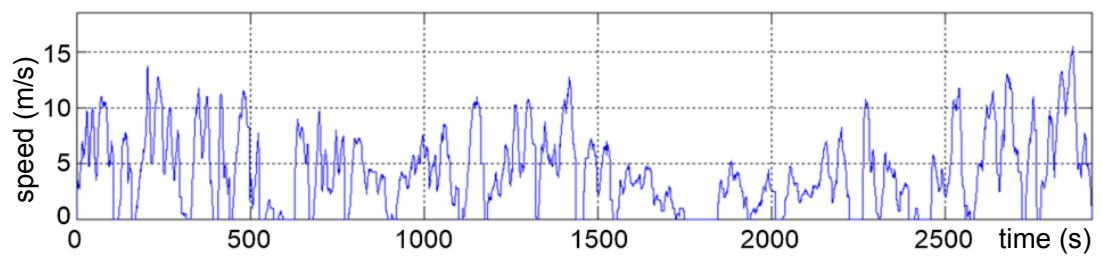

Figure 3: $\quad$ Speed profile of APS DP round trip.

The minimization of the $\left|d_{f}-d_{f}^{*}\right|$, being $d_{f}^{*}$ the reference fuel consumption in Table 2, provides the values $f_{0}$ and $C_{D}$, making possible the bus model definition for numerical code implementation.

\section{Equivalent electric bus}

The definition of an effective EBB fulfilling the service requirements in the Padova PUT meets some difficulties related to: 
- the poor operating experience of EBB commercial service in similar towns;

- the multiple technologies adopted for the on-board batteries, making troublesome a homogeneous performance comparison;

- the various vehicle characteristics adopted for the commercial models in terms of mass, seats, control system and energy recovery performances.

In order to overcome the above problems, a synthesis of the main bus commercial data is carried out for the vehicle characteristics. With reference to the battery technology, an extensive comparison focuses the choice on the Sodium Nickel Chloride (ZEBRA) battery (Dustmann [7]).

Its main features are good specific energy $(\approx 120 \mathrm{Wh} / \mathrm{kg})$, competitive purchasing cost (450-550 €/kWh), absence of memory effect, fault tolerance (5$10 \%$ of cells may fail before the battery can no longer be used), nearly constant delivered power for a wide depth of discharge (DOD) variation and higher operating life than the Li batteries (max 10-year period with 2200 cycles at least).The main drawbacks are not particularly critical and they regard the high operating temperature (between 270 and $350^{\circ} \mathrm{C}$ ) calling for accurate thermal management and lower energy density than the Li batteries $(\approx 180 \mathrm{Wh} / 1)$.

By elaborating the discharge curves at a constant power (voltage as a function of the output charge for different discharge rates) of a commercial module (FIAMM SoNick ${ }^{\circledR}$, Manzoni et al. [8] and Lodi et al. [9]), the discharge efficiency is obtained as the ratio between the instantaneous and the reference voltages, the latter correspondent to the value at $\mathrm{DOD}=0$ (Fig. 4(a)). A similar operation is applied for the charge efficiency calculation (Fig. 4(b)); however, in this case a power limit $(18 \mathrm{~kW})$ is imposed to avoid possible damages due to thermal stress. Such constraint is anyway acceptable, since according to several experiences in urban services, the energy recovery is unlikely exceeding $10 \%$ of the requested traction energy.

\subsection{Battery sizing procedure}

The battery capacity is related to the energy required for the same driving cycles of the ICE buses. Being $W_{\text {batt }, 0}$ the initial value at $\mathrm{DOD}_{0}=0.2$ (rated energy $\left.W_{\text {batt }}=W_{\text {batt }, 0} \cdot\left(1+D O D_{0}\right)\right)$, to prevent excessive performance deterioration (see Fig. 4) and unacceptable lifetime decrease, DOD is verified to be lower than the maximum allowable limit $\mathrm{DOD}_{\mathrm{M}}=0.8$ at the end of the operating range $D_{e l}$. Failing that, $W_{\text {batt }}$ is iteratively updated until $\mathrm{DOD}<\mathrm{DOD}_{\mathrm{M}}$.

The calculation procedure considers the following assumptions:

- maximum bus length $L_{M}=12 \mathrm{~m}$ and operating range $D_{e l}=140 \mathrm{~km}$ (driving cycles are repeated until the travelled distance approximates $D_{e l}$ );

- unvaried values with respect to the ICE buses as for the friction and drag coefficients, the requested auxiliary power and the payload mass;

- $\quad$ given electric drive specific power $\left(p_{e l}=0.2 \mathrm{~kW} / \mathrm{kg}\right)$ and battery specific energy $\left(w_{\text {batt }}=120 \mathrm{Wh} / \mathrm{kg}\right)$;

- constant wheel to battery terminals efficiency $\eta_{e l}=0.8$,including mechanical transmission, electric machine and power converter losses, regardless of the traction/braking operation and of the power value. 

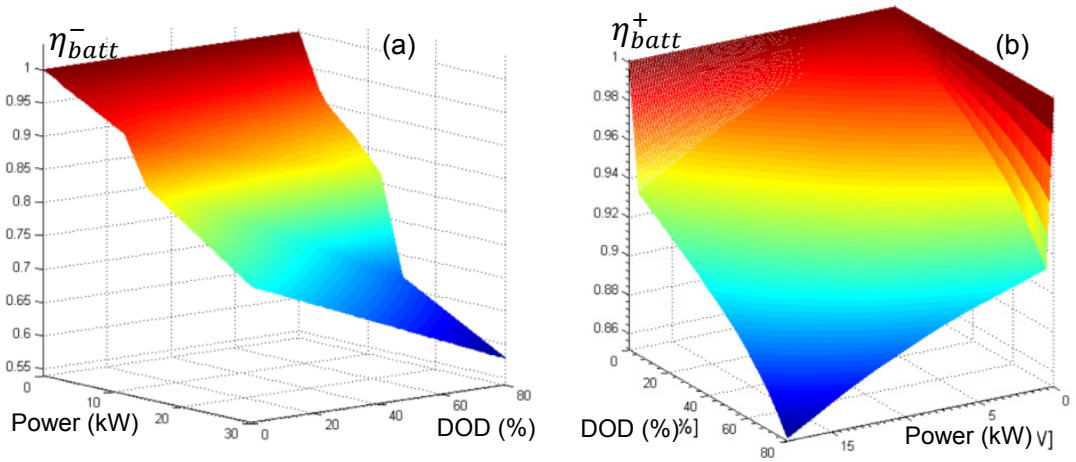

Figure 4: ZEBRA battery efficiency $\eta_{\text {batt }}$ as a function of the output power and the DOD; (a) discharge operation; (b): charge operation.

Table 3: Equivalent bus characteristics.

\begin{tabular}{|c|c|c|c|c|}
\hline $\begin{array}{c}\text { Length } \\
L(\mathrm{~m})\end{array}$ & $\begin{array}{c}\text { Battery rated energy } \\
W_{\text {batt }}(\mathrm{kWh})\end{array}$ & $\begin{array}{c}\text { Max electric drive power } \\
P_{M, e l}(\mathrm{~kW})\end{array}$ & $\begin{array}{c}\text { Tare } \\
M_{t}(\mathrm{~kg})\end{array}$ & $\begin{array}{c}\text { Vehicle mass } \\
M_{\text {bus }}(\mathrm{kg})\end{array}$ \\
\hline 8 & 148.4 & 200 & 6081 & 9666 \\
\hline 11 & 190.8 & 250 & 8392 & 13658 \\
\hline 12 & 190.8 & 270 & 8560 & 14000 \\
\hline
\end{tabular}

With reference to the $h$-th iteration, the total vehicle mass $M_{b u s, h}$ is evaluated as:

$$
M_{b u s, h}=M_{t}+M_{\text {pass }}+\frac{P_{M, e l, h-1}}{p_{e l}}+\frac{W_{\text {batt }, h-1}}{w_{\text {batt }}}, P_{M, e l, h-1}=k_{M} P_{M, h-1}
$$

with $P_{M, e l, h-1,} P_{M, h-1}$ maximum electric drive and traction power evaluated at the (h-1)-th iteration and $k_{M}=1.2$ precautionary overrating index for the electric drive power. After evaluating the battery output power $P_{\text {batt }, h}$, the energy $\Delta W_{\text {batt, } h}$ elaborated between the time instants $t_{h-1}$ and $t_{h}$ are estimated as:

$$
\begin{gathered}
\Delta W_{\text {batt }, h}^{-}=\int_{t_{h-1}}^{t_{h}} \frac{\left\langle P_{\text {batt }}\right\rangle_{h}}{\eta_{\text {batt }}^{-}\left(\left\langle P_{\text {batt }}\right\rangle_{h}, D O D_{h-1}\right)} d t \\
\Delta W_{\text {batt }, h}^{+}=\int_{t_{h-1}}^{t_{h}}\left\langle P_{\text {batt }}\right\rangle_{h} \cdot \eta_{\text {batt }}^{+}\left(\left\langle P_{\text {batt }}\right\rangle_{h}, D O D_{h-1}\right) d t
\end{gathered}
$$

where superscripts '-', '+' denote discharge and charge operation respectively and $\left\langle P_{b a t t}\right\rangle_{h}=\left(P_{b a t t, h}+P_{b a t t, h-1}\right) / 2$. The residual battery energy and thus DOD are therefore updated until the operating range completion.

The main data of the equivalent electric bus, obtained from the above analysis, are reported in Table 3 . Both the battery energy and the electric drive power are rounded to available commercial sizes. It is worth pointing out that the specific energy per $\mathrm{km}$ at no-load is included in $0.1-0.13 \mathrm{kWh} / \mathrm{km} /$ ton range typical of several commercial models. 


\subsection{Optimized battery management}

Recently, some transport companies investigated the possibility to adopt exchangeable batteries coupled to recharging stations (battery swap stations), deemed to represent a competitive solution for development of sustainable and reliable EBB urban services (Kakuhama et al. [10], Jin-long et al. [11]). The main benefits are the reduced recharging time limited to battery package replacement, the load reduction on the electrical infrastructure with respect to rapid charging systems and the extended battery lifetime due to the optimized DOD management and charging conditions.

However, the latter feature can only be achieved by a suitable supervision strategy regulating the daily battery exchange at the terminal stations between the buses in service on the same route. To this purpose, an iterative procedure based on a "random restart hill climbing" optimization technique is developed to find an optimal assignment of the available $m_{\text {batt }}$ batteries to a fleet of $n_{\text {bus }}$ buses, trading off technical and economical requirements ( $m_{\text {batt }}$ is a conservative estimate of the number of batteries according to the total daily mileage). As a first step, given the driving cycle and the consequent available range for a predefined DOD, the procedure randomly generates an initial $n_{\text {bus }} \times m_{\text {batt }}$ matrix representing the battery assignment at the terminal station to each bus in service, satisfying predefined constraints (one-to-one battery-bus assignment at each timetable interval, maximum number of daily exchanges, DOD consistency with minimum required operating range, minimum allowable DOD for recharging). The matrix elements are then varied in turns, retaining only favourable changes, provided that the predefined constraints are fulfilled. To avoid the entrapment into local minima, the search process is repeatedly restarted from completely detached initial sets of values.

In the calculation procedure, the efficiency decay with the number of recharging cycles is taken into account, estimating that at the end of its life $(\approx 2200$ cycles, 11 years $)$ the battery experiments a performance decrease of about $20 \%$. A further penalty of $-1 \%$ /year is applied to the EBB powertrain efficiency, complying with experimental observations. The minimum battery number $m_{\text {batt }}$ fulfilling the range requirements must therefore reckon with the worst efficiency condition.

An example of optimized battery assignment matrix for $8 \mathrm{~m}$ long bus route with $n_{\text {bus }}=5, m_{\text {batt }}=7$ is shown in Table 4 , corresponding to nearly 8 hours of timetable service. The time, given in minutes, is computed since bus \#4 starts its service.

The round trip on this route (APS DP) is about $14.5 \mathrm{~km}$ long and takes on average about $66 \mathrm{~min}$. The flag ' 0 ' denotes inactive intervals, the other values identify each specific battery: it can be seen that only one battery exchange occurs for each bus, favouring fully charged batteries, while chances for replacement at the bus terminal- represented by greyed cells - vary from 5 to 7 , depending on the bus number. The battery stored energy dependence on time (evaluated at the terminal station) is reported in Fig. 5. Only in two cases the batteries are recharged (ascending dashed line marked by \#1 and \#2) since they 
Table 4: Example of a battery assignment matrix for \#DP route $\left(n_{b u s}=5\right.$, $m_{\text {batt }}=7$ ).

\begin{tabular}{|c|c|c|c|c|c|c|}
\hline Slot & Time & Bus 1 & Bus 2 & Bus 3 & Bus 4 & Bus 5 \\
\hline 1 & 0 & 0 & 0 & 0 & 2 & 0 \\
\hline 2 & 2 & 0 & 0 & 0 & 2 & 0 \\
\hline 3 & 7 & 0 & 1 & 0 & 2 & 0 \\
\hline 4 & 15 & 0 & 1 & 0 & 2 & 5 \\
\hline 5 & 17 & 0 & 1 & 0 & 2 & 5 \\
\hline 6 & 35 & 3 & 1 & 0 & 2 & 5 \\
\hline 7 & 37 & 3 & 1 & 0 & 2 & 5 \\
\hline 8 & 52 & 3 & 1 & 0 & 2 & 5 \\
\hline 9 & 54 & 3 & 1 & 0 & 2 & 5 \\
\hline 10 & 72 & 3 & 1 & 0 & 2 & 5 \\
\hline 11 & 84 & 3 & 1 & 0 & 2 & 5 \\
\hline 12 & 87 & 3 & 1 & 0 & 2 & 6 \\
\hline 13 & 102 & 3 & 1 & 0 & 2 & 6 \\
\hline 14 & 117 & 3 & 1 & 0 & 2 & 6 \\
\hline 15 & 129 & 3 & 1 & 7 & 2 & 6 \\
\hline 16 & 143 & 3 & 1 & 7 & 2 & 6 \\
\hline 17 & 147 & 3 & 1 & 7 & 2 & 6 \\
\hline 18 & 155 & 3 & 1 & 7 & 2 & 6 \\
\hline 19 & 167 & 4 & 1 & 7 & 2 & 6 \\
\hline 20 & 180 & 4 & 1 & 7 & 2 & 6 \\
\hline 21 & 193 & 4 & 1 & 7 & 2 & 6 \\
\hline
\end{tabular}

\begin{tabular}{|c|c|c|c|c|c|c|}
\hline Slot & Time & Bus 1 & Bus 2 & Bus 3 & Bus 4 & Bus 5 \\
\hline 22 & 206 & 4 & 1 & 7 & 2 & 6 \\
\hline 23 & 219 & 4 & 1 & 7 & 2 & 6 \\
\hline 24 & 232 & 4 & 1 & 7 & 2 & 6 \\
\hline 25 & 245 & 4 & 3 & 7 & 2 & 6 \\
\hline 26 & 258 & 4 & 3 & 1 & 2 & 6 \\
\hline 27 & 271 & 4 & 3 & 1 & 5 & 6 \\
\hline 28 & 284 & 4 & 3 & 1 & 5 & 6 \\
\hline 29 & 293 & 4 & 3 & 1 & 5 & 6 \\
\hline 30 & 297 & 4 & 3 & 1 & 5 & 6 \\
\hline 31 & 310 & 4 & 3 & 1 & 5 & 6 \\
\hline 32 & 336 & 4 & 3 & 1 & 5 & 6 \\
\hline 33 & 349 & 4 & 3 & 1 & 5 & 2 \\
\hline 34 & 362 & 4 & 3 & 1 & 5 & 2 \\
\hline 35 & 378 & 4 & 0 & 1 & 0 & 2 \\
\hline 36 & 382 & 4 & 0 & 1 & 0 & 2 \\
\hline 37 & 387 & 4 & 0 & 1 & 0 & 2 \\
\hline 38 & 402 & 4 & 0 & 1 & 0 & 2 \\
\hline 39 & 412 & 4 & 0 & 1 & 0 & 2 \\
\hline 40 & 422 & 4 & 0 & 1 & 0 & 2 \\
\hline 41 & 434 & 4 & 0 & 1 & 0 & 2 \\
\hline 42 & 447 & 4 & 0 & 1 & 0 & 2 \\
\hline
\end{tabular}

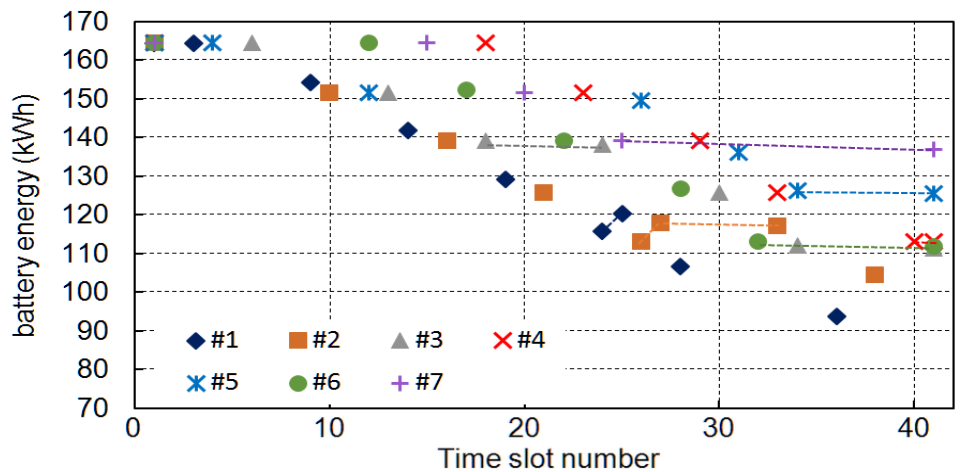

Figure 5: Variation of the energy stored in the batteries $\# 1, \ldots, \# 7$ as a function of the time slot number reported in Table 4.

reached the maximum allowable DOD; in the other cases, self-discharge is allowed (slightly descending dashed line), to avoid ineffective recharge that negatively affects the battery life.

The implementation of voltage vs DOD characteristic at constant charging power also allows estimating the additional stored energy and the electric energy supplied by the grid. The latter quantity enables both operating cost calculation 
(differentiating daytime and night-time tariffs) and estimation of centralized pollutant emissions related to the electric $\mathrm{kWh}$ production.

By assuming different policy scenarios and using an estimation of the main expenditure items, the algorithm provides an overall average annual cost weighted on the travelled distances - of about $0.48 € / \mathrm{km}$, which is competitive with the actual well-established technologies [12].

\section{Emission estimation}

The ICE and EB equivalent buses enable to represent the fleet operation on both specific routes and the overall APS transport network. Once an optimal battery management for the EBB fleet is defined, the electric transport environmental sustainability can be assessed (e.g., by estimating the external costs) comparing the emissions due to the electrical energy production with the ICE fleet ones.

The operation of the equivalent ICE buses is simulated by the software Advisor $^{\circledR}$ (Markel et al. [13]), by implementing the main data of both the vehicle and the power devices as well as the driving cycle. By such code, the actual operation of the power components can be reproduced more accurately (e.g., thermal behaviour, efficiency dependence on torque and speed working points) and then the fuel consumptions and gas emissions can be more dependably assessed.

As for the EB equivalent bus, the specific emissions are determined by a weighted sum of the $\mathrm{kg} / \mathrm{kWh}$ values corresponding to the Italian primary energy mix (ISPRA [14]) and to the EU-27 one (IEA [15]) for the 10\% imported quota.

The model consistency is verified comparing the fuel consumptions determined by preliminary simulations with the values of Table 2 (Fig. 6). Results substantially agree, even if the model ones are undervalued (in particular for $12 \mathrm{~m}$ bus) with respect to Advisor ${ }^{\circledR}$, which relies on real engine efficiency maps.

As for the emission evaluation, the driving cycles of APS DP and \#9 routes are examined, considering the $8 \mathrm{~m}$ and $11 \mathrm{~m}$ long equivalent buses, respectively, and assuming as payload the $20 \%$ of the bus capacity. A 10 -year reference time span is adopted to evaluate the EBB economic sustainability, unlike the ICE bus configurations (see Table 2). The assessment of the primary energy consumption takes into account the battery performance decay and its possible replacement. By the battery management optimization, the values $m_{\text {batt }}=6$ and $m_{\text {batt }}=8$ are obtained for $8 \mathrm{~m}$ and $11 \mathrm{~m}$ EBBs, respectively, enabling an 8 year operation before replacement. Fig. 7 compares the specific energy consumption (in tonne of oil equivalent) and gas emissions for different bus length and fuels.

Unfortunately, emission types in ICE and EB buses cannot be directly compared, except for $\mathrm{NO}_{\mathrm{x}}$ and $\mathrm{PM}$ emissions. HCs (Hydrocarbons) are included in VOCs (Volatile Organic Compounds) and then are somewhat related to NMVOCs (Non-Methane VOC), but estimation is rough. The results evidence that: 
- $\quad$ EBB primary energy consumption is nearly halved with respect to the ICE buses; as for the latter, the $\mathrm{CNG}$ fueled bus has $12 \%$ lower consumption than the same length diesel fueled vehicle;

- $\quad \mathrm{CNG}$ buses considerably contribute to $\mathrm{CO}$ and $\mathrm{NO}_{\mathrm{x}}$ emissions, even if some values implemented in Advisor ${ }^{\circledR}$ (mainly for $\mathrm{CO}$ ) could be outdated, but anyway consistent with literature data (Eilbert and Kahan [16]); on the contrary, $\mathrm{PM}$ is negligible, similarly to $\mathrm{EBBs}$;

- $\quad$ EBBs enables a reduction by $1 / 3$ of both $\mathrm{HC}$ compounds and $\mathrm{NO}_{\mathrm{x}}$ emissions; however, they are more sensitive to bus length and have appreciable $\mathrm{SO}_{2}$ emissions (not evaluated for ICE buses) because of the remarkable thermoelectric component in the Italian energy mix.

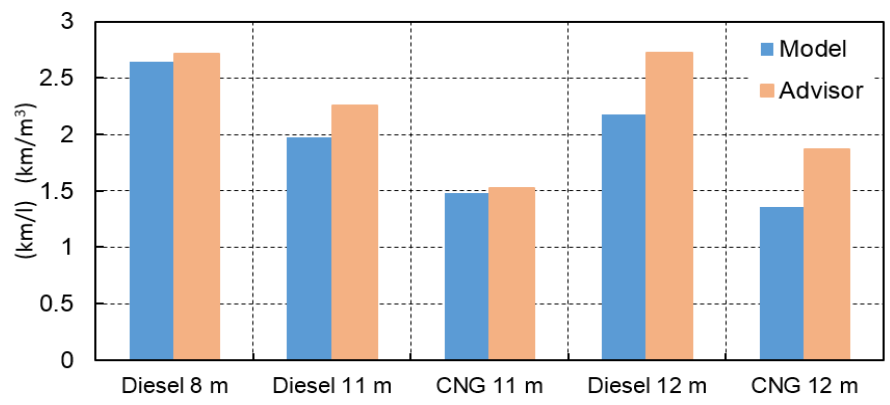

Figure 6: Comparison of the fuel consumption by the bus model and Advisor ${ }^{\circledR}$.

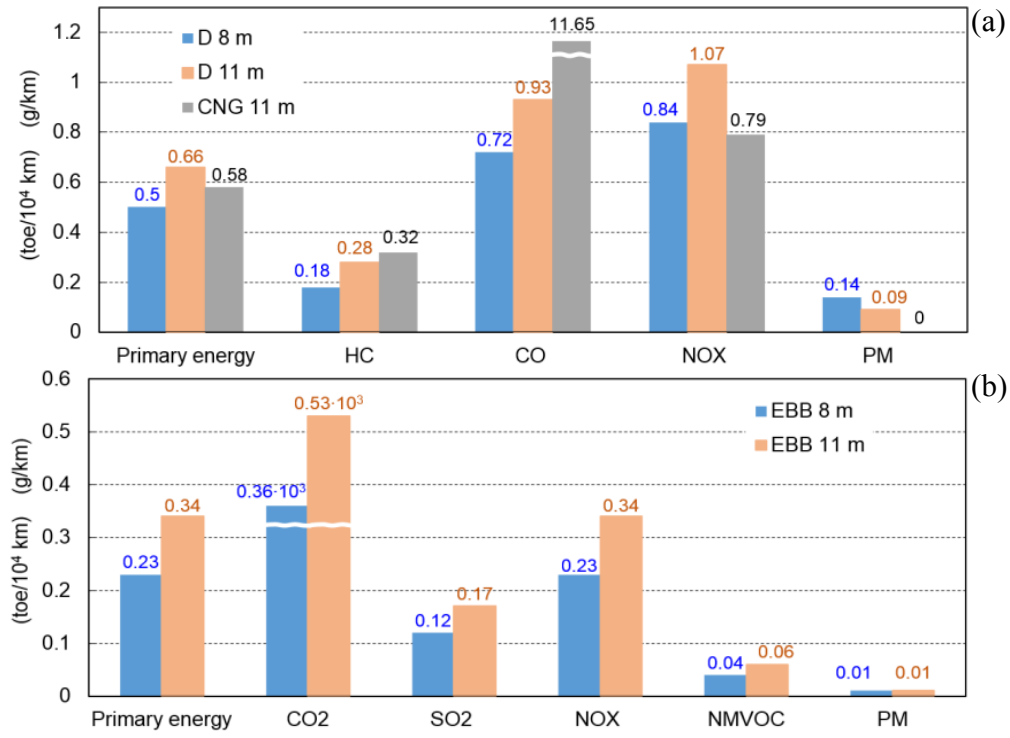

Figure 7: $\quad$ Specific energy consumption and gas emissions for $8 \mathrm{~m}$ and 11 long buses; (a): ICE buses (D: diesel type); (b): EBBs. 
By way of example, replacing $8 \mathrm{~m}$ diesel buses with corresponding EBBs on a typical urban route, the following savings can be attained: $-58 \%$ primary energy consumption, $-72.6 \%$ NOx, $-77.7 \%$ from $\mathrm{HC}$ and NMVOC comparison and

$-92.8 \%$ PM. In addition to such benefits, a significant noise reduction is expected.

\section{Conclusion}

The proposed methodology is aimed to assess the environmental sustainability of a new fleet electric battery buses in the urban public transport system of the city of Padova. The actual bus fleet being characterized, characteristics and operation of the electric buses provided by ZEBRA batteries are defined, adopting an optimized strategy for the battery replacement and recharging.

The results obtained by the simulation of the bus service on specific urban routes substantially confirm that the substitution of the conventional buses with electric buses is convenient as regards both the primary energy consumption and pollutant emissions. Though the introduction a small sized fleet $(8 \mathrm{~m}$ long vehicles) represent the most viable solution, higher benefits can be obtained by replacing buses with larger transport capacity (11 m long vehicles), meeting most of the public transport service requirements.

\section{Acknowledgements}

Special acknowledgments to APS Holding SpA [5] and FIAMM Group SpA [9] for the provided data and assistance during elaborations.

\section{References}

[1] EU White Paper, Roadmap to a Single European Transport Area Towards a Competitive and Resource Efficient Transport System, 2011.

[2] ASSTRA, Autobus e Investimenti 2011, $9^{\text {th }}$ Convegno Nazionale ASSTRA, Desenzano del Garda (Italy), May 23-25, 2011.

[3] Italian National Institute of Statistics (ISTAT), Mobilità Urbana 2011, Focus Statistiche, June 14, 2013.

[4] ARPAV, Relazione Generale - INEMAR Veneto 2007/8, Inventario regionale delle emissioni in atmosfera INEMAR Veneto, September 2013.

[5] APS Holding, Bilancio di Sostenibilità 2012, October 2013.

[6] Andriollo, M., Martinelli, G., Morini, A., Stellin, S. \& Tortella, A., Rating of the Power Components in Series-hybrid Buses with Different Supply Control Strategies. Symp. on Power Electronics, Electrical Drives, Automation \& Motion, May 23-26, Taormina (Italy), 2006.

[7] Dustmann, C. H., Advances in ZEBRA batteries, Journal of Power Sources, Vol. 127, 2004, pp. 85-92. 
[8] Manzoni, R., Metzger, M. \& Crugnola, G., Zebra Electric Energy Storage System: From R\&D to Market, HTE hi. tech. expo, Milan, November 2528, 2008.

[9] Lodi, G. Manzoni, R. \& Crugnola, G., Batteries for full electric and hybrid buses: fleet operation results and relevant battery improvements, $25^{\text {th }}$ World Battery, Hybrid and Fuel Cell Electric Vehicle Symp. \& Exhibition, Shenzhen, China, November 5-9, 2010.

[10] Kakuhama, Y., Kato, J., Fukuizumi, Y., Watabe, M., Fujinaga, T. \& Tada, T., Next-generation Public Transportation: Electric Bus Infrastructure Project, Mitsubishi Heavy Industries Technical Review, Vol. 48, No. 1, March 2011.

[11] Jin-long, Z., Xiao, L., Shou-yin, L., Hua-dong, Z.\& Hui, Q., Operation Mode Analysis of Electric Vehicle Charging and Battery Swap Station, $2^{\text {nd }}$ Intl. Conf. on Electronic \& Mechanical Engineering and Information Technology, Liaoning (China), September 7-9, 2012, pp. 1716-1719.

[12] De Lorenzi, A., Ottimizzazione della gestione di un parco di autobus elettrici per il servizio di trasporto pubblico della città di Padova, M.S. Thesis, ID N.45596, 2014 (in Italian).

[13] Markel, T., Brooker, A., Hendricks, T., Johnson, V., Kelly, K., Kramer, B., O'Keefe, M., Sprik, S. \& Wipke, K., ADVISOR: a systems analysis tool for advanced vehicle modeling, Journal of Power Sources, vol. 110, n. 2, August 2002, pp. 255-266.

[14] Italian Institute for Environmental Protection and Research (ISPRA), Trasporti: strumenti europei e nazionali per il risanamento della qualità dell'aria, n. 191, 2014.

[15] IEA, World Energy Outlook, 2011.

[16] Eilbert, A. \& Kahan, A., Proposed Exhaust Emission Rates for Compressed Natural Gas Transit Buses in MOVES2013, MSTRS MOVES Review Work group (U.S. EPA Office of Transportation \& Air Quality), September 25, 2012. 